\title{
Equilibrium
}

Quarterly Journal of Economics and Economic Policy

VOLUME 7 ISSUE 4, 2012

ISSN 1689-765X

Radosław Kurach*

Wroctaw University of Economics, Poland

\section{Stocks, Commodities ANd Business \\ Cycle Fluctuations - Seeking THE DiverSIFICATION BENEFITS}

\section{JEL Classification Codes: E32, F30, G11}

Keywords: stock and commodity markets, diversification benefits, business cycle fluctuations

\begin{abstract}
In this study we empirically verify the diversification potential of different commodity sectors for equity portfolios. We also try to find the explanation of varying cross-sectoral diversification benefits by verifying the relationship between macroeconomic variables and commodity indices. We employ correlation analysis for our purposes. The obtained results indicate that Precious Metal and Livestock are valuable equity portfolio diversifiers, while Industrial Metals volatility has much in common with the fluctuations of broad stock market.
\end{abstract}

\section{INTRODUCTION}

In the contemporary globalized world with free capital movements, the set of potential financial assets has expanded considerably and investors are no longer constrained to domestic stocks or bonds. That is why for many years investors looking for the diversification benefits (reducing portfolio risk while keeping the return constant) have been willing to invest a part of their

(C) Copyright Nicolaus Copernicus University Press

Date of Submission: January 28, 2012; date of acceptance: October 10, 2012

* Contact: e-mail: radoslaw.kurach@ue.wroc.pl, Wrocław University of Economics, ul. Komandorska 118/120, 53-345 Wrocław, Poland 
portfolio in foreign equities. According to the seminal paper by Markowitz (1952) the diversification gains are higher whenever the correlation coefficient between assets is lower. In the early studies international diversification of the domestic equity portfolio was believed to deliver the desired diversification results (Grubel 1968; Levy, Sarnat 1970). To understand the rationale of international investing one should think about the determinants of equities valuation. As equities are the means of property rights in the company, which is valued higher whenever it is able to generate higher profit, it is not surprising that stocks' returns are merely driven by business cycle fluctuations. However, due to information efficiency of the financial markets, equities' valuation reflects the expected state of the economy rather than current macroeconomic conditions. For this reason, stock market indices are often considered as leading indicators of the business cycle. Equity prices are the lowest before the economy reaches its bottom. As the economic growth accelerates and GDP rate of growth exceeds the potential output growth, equities reach its peak. According to AD-AS model in this phase of the business cycle inflation pressure start to emerge. Therefore, stocks are considered usually as poor inflation-hedgers. In the international context, when investors are able to purchase equities in two countries, which business cycles are not synchronized, it is possible that their stock markets also exhibit low correlation and the portfolio risk may be reduced. Nevertheless, we should think, if the business cycles in the contemporary world are really so different?

In the last twenty years numerous studies noted rising business cycle dependence. Artis, et al.(2009) analyzed the macro data across 25 emerging and advanced economies. In some cases the available time series were even 125 years long. Artiset al. (2009) observed rising business cycle correlations since 50s and accelerating since 1973, but mainly within a group of European and a group of English-speaking economies. Other empirical studies list the possible determinants of this phenomenon. Perhaps the most frequently discussed causes are foreign trade deepening (Baxter, Kouparitsas 2004) and liberalization of capital accounts (Imbs 2003). However, even the potentially unrelated factors can support the process of rising GDP correlation. Flood and Rose (2010) present the theoretical model and deliver some empirical support regarding the inflation targeting framework. According to their study, this popular strategy in modern central banking leads to higher business cycles synchronization than any other monetary policy framework. Finally, as we can expect, numerous papers confirmed also the diminishing diversification benefits from international equity investing (Sinquefield 1996; Niemczak 2010).

We can now presume that the type of the asset rather than domicile of the securities' issuer should be the dominant criterion for assets allocation deci- 
sions while seeking for diversification opportunities. In this study we would like to focus our attention on commodity investments.

Commodities areconsidered usuallyasgoodequity portfolio diversifiers. Numerous studies confirmed the stylized fact that adding the commodities to the US equities and bonds portfolio (Kaplan, Lummer 1998; Greer 2000), international equity portfolio (Laws and Thompson 2007) or even international stock and bond portfolio (Idzorek 2006), one can expect an improvement in the risk-adjusted return as measured for example by the Sharpe ratio.Economists frequently argue that commodities comparing to stocks or bonds have differenttiming response pattern to business cycle fluctuations, which leads to low correlations with the capital assets. Gorton and Rouwenhorst (2006 seven) analyzing US business cycles starting from 1959 found commodities prices to be more coincident (less leading) business cycle indicator comparing to bonds and equities. The purpose of this paper is to verify empirically the timing pattern of relationship between the equity, commodity prices and macroeconomic factors once again along with making two contributions to the existing literature.

First of all, commodities are rather heterogeneous group of assets, so we would like to distinguish five different groups in this asset class and verify the relationship between each commodity group and macroeconomic variables separately. We show that the timing pattern of our interest varies for the analysed groups, hence the diversification potential has been also varying.

Secondly, the existing studies that verify macro-commodities relationship employ usually very long (30-40 years) post-war data series. In this paper we focus our attention on last decade using monthly industrial production (IP) data instead of quarterly gross domestic product (GDP) to collect the sufficient number of observations that guarantees the robustness of the results. The verification method utilized in this study is the correlation analysis, which is frequently used to identify the lead/lag structure between different economic time series.

The paper continues as follows: in the next paragraph we start from discussing the fundamentals of commodity investments. Presenting the variety of commodity assets, we provide some theoretical explanation of business cycle - commodities co-movement and underline these points, which make commodities different from stocks and bonds in the discussed area. We deliver the empirical results confirming this pattern of co-movement as well. The next paragraph contains the detailed description of data and methodology. Later, we analyze the empirical results trying to find the economic rationale for the obtained numbers. In the last section we make concluding comments and describe possible direction for further research. 


\section{INVESTING IN COMMODITIES}

\section{Defining commodities}

Unlike stock and bonds it is not easy to define commodities in a few words as a separate asset class because of its significant heterogeneity. Figure 1. present the diversity of commodities sectors:

Figure 1. Commodity sectors - general classification

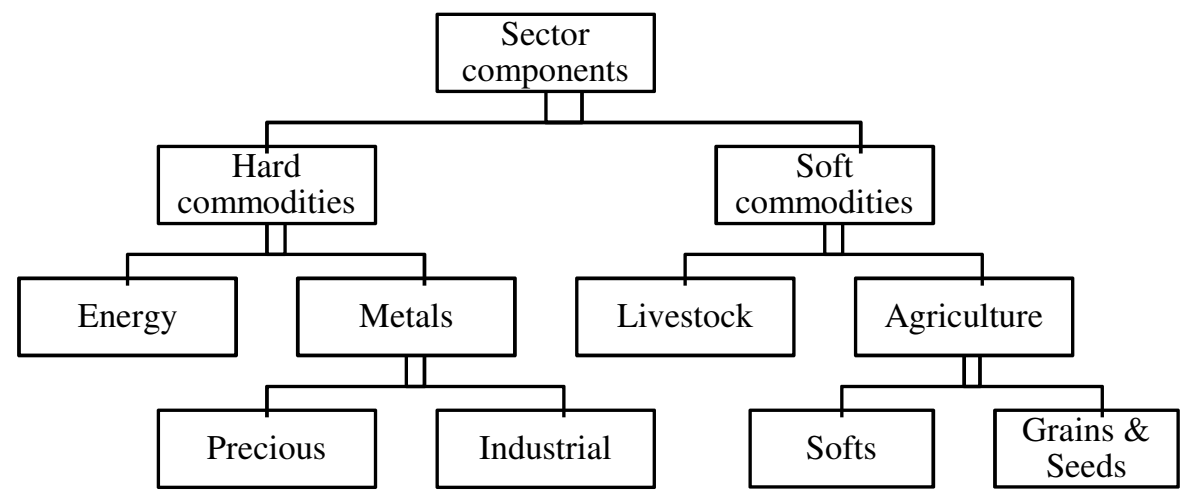

Source: Fabozzi et al. (2008, p. 8).

The example commodities for each sector are following (Fabozzi et al. 2008, p. 8):

- Energy: Brent Oil, Brent Oil, Crude Oil, Coal, Gas Oil, Heating Oil, Natural Gas, Unleaded Gasoline;

- Industrial Metals: Aluminum, Chrome, Copper, Lead, Mercury, Nickel, Selenium, Tin, Titanium, Zinc;

- Precious Metals: Gold, Iridium, Palladium, Platinum, Osmium, Rhodium, Ruthenium, Silver;

- Livestock: Feeder Cattle, Live Cattle, Live Hogs, Pork Bellies;

- Agriculture Softs: Coffee, Cocoa, Cotton, Orange, Juice, Rubber, Sugar, Silk, Timber, Wool;

- Agriculture Grain\&Seeds: Azuki Beans, Barley, Canola, Corn, Millet, Oats, Oilseeds, Red Wheat, Rice, Rye, Sorghum, Soybeans, Soybean Meal, Wheat. 
Idzorek (2006, p. 4) states commodities are: "real return, real assets that are part of both the consumable/transformable super asset class and the store-of-valuesuper asset class." Traditionally, by real assets investors have recognized tangible assets like commodities or real estates. Real return assets is a broader category spanning real assets and identify these investments that are perceived as the unexpected inflation hedgers. Besides real assets we can find here for example Treasury Inflation Protected Securities (TIPS) (Strategic Investment Solutions 2011, p. 2).The latter part of commodities definition is based on the classification created by Greer (1997), who divided investable assets into three large groups (super asset classes): capital assets, consumable/transformable assets and store-of-value assets. In the first group we can find the assets that provide an ongoing source of value thatcan be measured by discounting the future cash flows. The example assets are stocks, bonds and real estates. The second class consists of assets that do not generate a stream of cash flows, but a single cash flow. Finally, store-ofvalue assets like fine-art, are not consumed and do not generate income, although they have monetary value.As we see commodities falls into two of three distinguished groups as most of them are consumable/transformable, but a few, especially precious metals may be treated as store-of-value assets at the same time.

\section{COMMODITIES AND BUSINESS CYCLE}

Theory predicts, that commodities react to business cycle differently than stocks and bonds, hence we should expect here potential diversification benefits. Anson (2009, pp. 329-332) lists three reasons why this might be true.

First of all, inflation usually leads to higher commodities prices, while having the detrimental impact on stocks and bonds valuation. Frequently, rising commodity prices are the source of inflation itself (negative supply shocks).

Secondly, commodities reflect short-term expectations, while stocks and bonds valuation is driven mainly by rather long-term forecasts. For example, rising inflation expectations due to overheating the economy leads to an increased supply of stocks and bonds. On the other hand, commodities should react positively as it indicates higher demand for raw materials.

The last argument is based on economic production process. The neoclassical theory states that marginal revenue (price) should equal the marginal cost. Having three factors of production, namely capital, labour, and raw materials, the total return to these three factors should equal the price of production. Assuming sticky wages in the short run, which is not very strong 
assumption, for any given price level an increase in the return to capital must be compensated by a decrease in the return to raw material and vice versa. Therefore, capital assets (stocks and bonds) should be negatively correlated with commodities.

The empirical research seems to support the above mentioned theoretical considerations. In one of the early studies Goldman Sachs\&Co. (1996) confirmed countercyclical movement of traditional investing assets and found commodities responding positively to current macroeconomic conditions. Hess et al. (2008) focused their attention on a setof seventeen US macroeconomic announcements and its impact on commodity, equity and bond prices for the sample period 1989-2005. They analysed this relationship under two frameworks: unconditionally and conditionally on business cycle phase, however. The unconditional model identified significant positive relationship between commodity prices and inflation measures, and significant negativeimpact of the overall price level on stocks and bonds. This framework did not find any response pattern of commodities to other macroeconomic news describing real economy, different from stocks (positive relationship) and bonds (negative relationship). When the business cycle phase dummy was implemented into the model, commodities were found to react positively to production releases during the recession periods, while the relationship was still insignificant in the expansion phase. This puzzling result was explained in the following way: "During expansions, unexpectedly high real activity announcements signal higher demand for commodities as input goods and unexpectedly high inflation news signal higher demand for commodities as inflation hedge. But at the same time both types of news are connected with substantial fears of rising interest rates which are negatively related to commodity prices due to rising storage costs and portfolio shifting into bonds. As a consequence, both effects cancel out each other during expansions. In contrast, during recessions interest rates are much less of a concern and therefore the positive effects prevail." (Hess et al. 2008, pp. 12-13). Summing up, comparing to other assets a different response pattern of commodities to macroeconomic news make them valuable equity portfolio diversifiers. The positive relationship between commodity prices and inflation was also confirmed in the studies by Camacho and Perez-Quiros (2011) for Latin America and by Gubler and Hertweck (2011) for US data using SVAR methodology. 


\section{DATA AND METHODOLOGY}

In this study we use monthly data for the period 01.2001-12.2010.

For equity and commodity indices we calculate monthly logarithmic returns using closing indices values for the last business day of each month. All indices are USD denominated. As a measure of stock market performance the Standards\&Poors 500 Composite index (SP) is employed. The overall commodity market performance is measured by Standard\&Poors Excess Return Goldman Sachs Commodity Index (GSCI). This index is frequently used as a benchmark for commodity investments. The main features of this measure are following:

- a world-production weighted index. The quantity of each commodity in the index is determined by the average quantity of production in the last five years of available data;

- comprises as many commodities as possible; The rules of excluding commodities only to retain liquidity and investability in the underlying futures markets are applied;

- contains 24 commodities from all commodity sectors: six energy products, five industrial metals, eight agricultural products, three livestock products and two precious metals;

- the broad range of constituent commodities provides the GSCI with a high level of diversification, both across sub-sectors and within each sub-sector. Hence, highly idiosyncratic events are minimized. (Goldman Sachs, 2012)

The GSCI components and Dollar Weights as of October 31, 2011 are presented in the Table 1 .

It is clear that the Energy sector is the dominant driver of GSCI variation, hence the broad GSCI reflects mainly the performance of one sector.

We need to underline the fact of using Excess Return rather than Total Return index type. The difference is quite meaningful as Total Return commodity index represents the unleveraged returns that would be earned by holding only passive long positions in the commodity futures contracts. To be unleveraged, the position must be fully collateralized with T-bills. Greer (2000, p. 46) gives an example that an investor who wishes to purchase a ten-ton cocoa futures contract at $\$ 1.800$ per ton, needs to allocate $\$ 18.000$ from his portfolio at a risk-free rate to support that futures position. Hence, Fabozzi et al. (2008, pp. 23-24) states that total return can be decomposed into the following parts:the spot return, the roll return (generated by switching from the maturing futures contract into the next closestfutures contract), and the collateral return (the interest payment on the cashposition). In contrast to Total Return index, the Excess Return index is uncollateralized, in other words represents a leveraged spot position (Fabozzi et al. 2008, pp. 
23-28). As Hess et al. (2008, p. 5) suggest studying the excess return indices abstracts from the price response of the T-Bill collateral and is better suited to investigate the commodity-specific price responses.

Table 1. GSCI Dollar Weights (Oct. 31, 2011)

\begin{tabular}{|c|c|c|c|c|c|c|c|c|c|}
\hline Energy & 69,5 & $\begin{array}{c}\text { Industrial } \\
\text { Metals }\end{array}$ & 7 & $\begin{array}{c}\text { Precious } \\
\text { Metals }\end{array}$ & 3,9 & Agriculture & 15 & Livestock & 4,5 \\
\hline Crude Oil & 32,7 & Aluminium & 2,2 & Gold & 3,3 & Wheat & 2,8 & $\begin{array}{l}\text { Feeder } \\
\text { Cattle }\end{array}$ & 0,5 \\
\hline $\begin{array}{l}\text { Brent } \\
\text { Crude }\end{array}$ & 16,7 & Copper & 3,3 & Silver & 0,5 & $\begin{array}{l}\text { Kansas } \\
\text { Wheat }\end{array}$ & 0,7 & $\begin{array}{l}\text { Live } \\
\text { Cattle }\end{array}$ & 2,7 \\
\hline $\begin{array}{l}\text { Unleaded } \\
\text { Gasoline }\end{array}$ & 4,6 & Lead & 0,4 & & & Corn & 4,5 & $\begin{array}{l}\text { Lean } \\
\text { Hogs }\end{array}$ & 1,5 \\
\hline $\begin{array}{l}\text { Heating } \\
\text { Oil }\end{array}$ & 5,4 & Nickel & 0,6 & & & Soybeans & 2,3 & & \\
\hline GasOil & 7,2 & Zinc & 0,5 & & & Cotton & 1,3 & & \\
\hline $\begin{array}{l}\text { Natural } \\
\text { Gas }\end{array}$ & 2,8 & & & & & Sugar & 2,2 & & \\
\hline & & & & & & Coffee & 0,9 & & \\
\hline & & & & & & Cocoa & 0,3 & & \\
\hline
\end{tabular}

Note: Numbers in percentage points.

Source: Standard \& Poor's (2012).

Our target is to verify the relationship between macroeconomic variables and different commodity groups, hence we employ also commodity sector specific excess return indices: S\&P GSCI Energy (ENERG), S\&P GSCI Industrial Metals (INDM), S\&P GSCI Precious Metal (PRECM), S\&P GSCI Agriculture (AGR), S\&P GSCI Livestock (LIVE).

The set of examined macroeconomic variables consists of three figures for the US economy that are published monthly: Industrial Production (IP), Consumer Price Index (CPI)and Producer Price Index (PPI). In case of IP we used IP seasonally adjusted index. On the other hand,CPI and PPI are presented as monthly rates on y/y basis.

The equity and commodity data were obtained from Reuters Datastream, while the source of macroeconomic variables was CEIC Data.

We decided to use correlation analysis to verify the time dependence structure between stocks, commodities and macroeconomic variables. We look for the highest values of correlation coefficient in absolute terms for different leads or lags for each pair of variables. Each pair consists of stocks or commodity index and macroeconomic variable, hence we estimate 18 cross correlograms. This method is rather intuitive, delivers easily interpretable results and, what is more important, it is frequently used for determin- 
ing lead/lag structure between different economic variables (Fritsche, Marklein 2001; Mohanty et al. 2003).

The other important point of the methodological description part applies to the transformation of IP series. As we investigate the relationship between business cycle and the returns of equity and commodity assets we need to transform the IP series to isolate the cyclical component from the trend one. One way to eliminate the trend is to first difference the logarithm of IP. However, as Stock and Watson (1998, p. 6) state, first differencing leaves also a lot from the short-run noise that is present in the data series. Therefore, following Stock and Watson (1998) and Inklaar and deHaan (2001) we have decided to isolate the cyclical component using the Hodrick-Prescott (HP) filter. The HP filter minimizes the following formula:

$$
\left(y_{t}-g_{t}\right)^{2}+\lambda \sum_{t=2}^{n-1}\left[\left(g_{t-1}-g_{t}\right)-\left(g_{t}-g_{t-1}\right)\right]^{2},
$$

where $y_{t}$ denotes the raw series (in our case $\log$ IP), $g_{t}$ the growth component and $\left(y_{t}-g_{t}\right)$ the cyclical component. The first part measures the fitness, and the second is a measure of smoothness. The parameter $\lambda$ is the signal-to-noise ratio and weights the relative importance of the two conflicting goals in the loss function: when $\lambda=0$ the filter gives the original series; as $\lambda$ goes to infinity, the HP filter collapses to a linear trend. Hodrick and Prescott (1997) suggest a value of $\lambda=14400$ for monthly data and this value has been adopted in the estimates here."

\section{EMPIRICAL RESULTS}

As our main source of interest is the diversification potential of commodities for equity portfolio and the macroeconomic causes of this phenomenon, we start from the general outlook at the data series.

The annualized returns vary significantly from the lowest $-5,74 \%$ for Livestock to $15,02 \%$ for Industrial Metals. The latter result has been significantly affected by rising demand from the Chinese economy. It is quite unusual to see a negative return on SP for a decade, but it is due to unprecedented financial crisis we still face, however.

* From now on IP will denote the cyclical component of Industrial Production series isolated with HP filter. 
Table 2. Summary statistics of indices monthly returns

\begin{tabular}{|l|c|c|c|c|c|c|c|}
\cline { 2 - 8 } \multicolumn{1}{c|}{} & SP & GSCI & ENERG & INDM & PRECM & LIVE & AGR \\
\hline Mean & $-0,82 \%$ & $0,16 \%$ & $-1,06 \%$ & $10,00 \%$ & $15,02 \%$ & $-5,74 \%$ & $-0,98 \%$ \\
\hline Std. dev. & $16,66 \%$ & $25,74 \%$ & $33,39 \%$ & $24,16 \%$ & $17,82 \%$ & $14,74 \%$ & $22,43 \%$ \\
\hline Skewness & $-0,82$ & $-0,89$ & $-0,57$ & $-0,69$ & $-0,64$ & $-0,62$ & $-0,04$ \\
\hline Kurtosis & 1,51 & 2,29 & 1,02 & 2,58 & 1,95 & 0,93 & 0,51 \\
\hline Jarque-Bera & 19,72 & 41,69 & 11,6 & 42,62 & 27,08 & 11,91 & 1,31 \\
\hline$p$-value & 0,000 & 0,000 & 0,003 & 0,000 & 0,000 & 0,003 & 0,520 \\
\hline
\end{tabular}

Note: ' $p$-value' refers to the Jarque-Bera test of normality, where the null hypothesis states, that thedistribution is normal.

Source: own study.

In case of normal distribution the values of skewness and kurtosis statistics should be zero. As it is quite common for the financial assets returns series these parameters are mostly far from zero. In case of most of the analysed time series skewness is significantly lower than zero, indicating that returns distributions are skewed to the left. The only exception is AGR, where the distribution is nearly symmetrical. On the other hand, the values of kurtosis are mostly well above zero. Hence, the investigated returns distributions have a more acute peak around the mean and fatter tails comparing to normal one. Finally, the Jarque-Bera test rejects the null hypothesis on normality at $1 \%$ significance level for the majority of indices and the only exception is again the agriculture sector.

Now we move to correlation analysis. Before we start to assess the degree of interdependence between variables we need to verify the stationarity of the investigated series. Unless time series are stationary, we are not able to obtain meaningful sample statistics.

We use two standard tests for this purpose: Augmented Dickey-Fuller (ADF) and Kwiatkowski-Phillips-Schmidt-Shin (KPSS). In case of ADF test, the null hypothesis states that series has a unit root (variable is not stationary), while the null of KPPS states thatvariable is stationary. The test statistics for both of the tests have been presented in Table 3 and 4. 
Table 3. Stationarity tests' results -- commodity and equity indices

\begin{tabular}{|c|c|c|c|c|c|c|c|}
\hline Test & SP & GSCI & ENERG & INDM & PRECM & LIVE & AGR \\
\hline ADF & $\begin{array}{c}- \\
8,76^{* * * *}\end{array}$ & $\begin{array}{c}- \\
8,286 * * *\end{array}$ & $\begin{array}{c}- \\
8,050 * * *\end{array}$ & $\begin{array}{c}- \\
8,050 * * *\end{array}$ & $\begin{array}{c}- \\
12,590 * * *\end{array}$ & $\begin{array}{c}- \\
9,506^{* * *}\end{array}$ & $\begin{array}{c}- \\
10,121 * * *\end{array}$ \\
\hline KPPS & 0,101 & 0,074913 & 0,08961 & 0,085514 & 0,13436 & 0,148725 & 0,127008 \\
\hline
\end{tabular}

Note: $* * *$ - significant at $1 \%, * *$ - significant at $5 \%, *$ - significant at $10 \%$.

Source: own study.

Table 3. Stationarity tests' results - macroeconomic variables

\begin{tabular}{|l|c|c|c|}
\hline Test & IP & CPI & PPI \\
\hline ADF & $-3,2548^{* *}$ & $-3,53356^{* * *}$ & $-2,76553^{*}$ \\
\hline KPPS & 0,054799 & 0,199867 & 0,100955 \\
\hline
\end{tabular}

Note: $* * *$ - significant at $1 \%, * *$ - significant at $5 \%, *$ - significant at $10 \%$.

Source: own study.

In case of all of the analysed variables KPPS test statistics are insignificant at $10 \%$ value, which strongly supports the null on stationarity. ADF test results lead also to the similar conclusion as in eight of three cases null hypothesis on unit root is rejected at $1 \%$ significance level, in one case at $5 \%$ and PPI was found to be significant at $10 \%$ level. The identified stationarity of the investigated series enables us to run correlation analysis.

We start from the contemporaneous correlations, which indicate diversification potential of different assets. Definitely, the risk reduction is higher, when correlation coefficient is lower, ceteris paribus.

What is especially interesting for us are of course correlation coefficients between SP and other assets, as we look for the diversifiers of equity portfolio. In general, correlation between SP and GSCI is quite moderate confirming the stylized fact that commodities exhibit diversification potential. However, analysing separately five commodity sectors we see that the degree of co-movement with equities varies significantly. While Precious Metals exhibit quite low interdependence, Industrial Metals returns have more in common with SP than with broad commodity index. 
Table 4. Indices returns correlation matrix

\begin{tabular}{|l|r|r|r|r|r|r|r|}
\cline { 2 - 8 } \multicolumn{1}{c|}{} & \multicolumn{1}{c|}{ SP } & \multicolumn{1}{c|}{ GSCI } & ENERG & \multicolumn{1}{c|}{ INDM } & PRECM & \multicolumn{1}{c|}{ LIVE } & AGR \\
\hline SP & 1 & & & & & & \\
\hline GSCI & 0,319098 & 1 & & & & & \\
\hline ENERG & 0,23643 & 0,97817 & 1 & & & & \\
\hline INDM & 0,577474 & 0,546893 & 0,451208 & 1 & & & \\
\hline PRECM & 0,088552 & 0,323309 & 0,275231 & 0,302663 & & & \\
\hline LIVE & 0,107432 & 0,186866 & 0,130002 & 0,152013 & $-0,01039$ & & \\
\hline AGR & 0,342334 & 0,390503 & 0,242994 & 0,392641 & 0,354246 & 0,068231 & 1 \\
\hline
\end{tabular}

Source: own study.

Trying to find some explanation of the observed varying diversification benefits phenomenon we have estimated the values of correlation coefficients between the macroeconomic series and the analysed indices for different leads/lags which are denoted by $i$. Thus, for a given pair of macro variable, $X_{t}$, and equity/commodity index variable, $Y_{t}, \rho_{ \pm i}\left(X_{t}, Y_{t \pm i}\right)$ denotes the correlation between $X_{t}$, and $Y_{t}$ at displacement $\pm i$. The maximum value of $\left|\rho_{ \pm i}\right|$ is chosen for $i \leq 18$. Table 6 displays the results.

Table 5. Leads or lags of the maximum absolute values of correlation coefficients between the given index and selected macroeconomicvariable

\begin{tabular}{|l|c|c|c|c|c|c|}
\hline \multirow{2}{*}{ Index Macro v. } & \multicolumn{2}{|c|}{ IP } & \multicolumn{2}{c|}{ CPI } & \multicolumn{2}{c|}{ PPI } \\
\cline { 2 - 7 } & $\boldsymbol{i}$ & $\boldsymbol{\rho}_{ \pm i}$ & $\boldsymbol{i}$ & $\boldsymbol{\rho}_{ \pm i}$ & $\boldsymbol{i}$ & $\boldsymbol{\rho}_{ \pm i}$ \\
\hline SP & -8 & 0.3122 & -10 & 0.2536 & -10 & 0.3136 \\
\hline GSCI & -5 & 0.3450 & -7 & 0.3882 & -8 & 0.4434 \\
\hline ENERG & -5 & 0.3211 & -7 & 0.3721 & -7 & 0.4159 \\
\hline INDM & -9 & 0.3145 & -8 & 0.3531 & -8 & 0.3818 \\
\hline PRECM & -9 & 0.1340 & 1 & -0.1853 & -11 & 0.1681 \\
\hline LIVE & 9 & -0.2416 & 9 & -0.1801 & -2 & 0.1919 \\
\hline AGR & -6 & 0.2489 & -8 & 0.2911 & -8 & 0.3041 \\
\hline
\end{tabular}

Source: own study.

At first, we compare the results for broad indices. We see that SP leads each of the analyzed macroeconomic variables earlier than GSCI, which confirms the stylized fact that has already been mentioned in this text. How- 
ever, the values of correlation coefficients are higher in this latter case. In case of nominal variables (CPI and PPI) this may be attributed to the fact that rising commodity prices are the source of inflation itself.In case of PPI we should again come back to the another stylized fact that equity prices reflect rather long term expectations, while commodities discount nearby future. It is more difficult to forecast the more distant events, so the precision of the long-term forecasts is lower comparing to the short term ones. Hence, the famous quote of Paul Samuelson (1966) seems to work: "Wall Street indexes predicted nine out of the last five recessions!"

The analysis for the separate commodity groups reveals some other interesting regularities, however. As it is not surprising that ENERG behaves much like GSCI, INDM leads the macroeconomic variables similarly to SP. This observation enables us to confirm the conclusion that from all commodity sectors Industrial Metals have exhibited the lowest diversification potential for equity portfolios.

On the other hand, we have PRECM, LIVE, AGR which seem to be quite unaffected by business cycle fluctuations as measured by IP, but one of them - AGR exhibits moderate correlation with inflation variables. To explain this phenomenon, in case of Precious Metals,we should recall the fact that these commodities serve not only as the production inputs, but also as the store of value. The debate regarding rising gold and silver prices has been very intensive and many determinants have been already discussed (Demidova-Menzel and Heidorn 2007) however, fears regarding the development of global economy seem to be the dominant factor nowadays.

The analysed soft commodities represent necessity goods, so at least on the theoretical ground they should be rather irresponsive to income fluctuations. This view has been confirmed by our empirical research, but mainly for the livestock sector. The behaviour of agricultural products prices is surprising to some extent, however. The observed higher correlation between CPI and AGR may be explained by the phenomenon of agflation. This term reflects the shock to food prices that took place in 2007-2008. As Bernstein and Rasco (2007, p. 1) state: "Food prices are rising, putting upward pressure on producer and consumer inflation. Agflation has begun. Given the expanding constraints on food supply, the changing demand for food, and the entrance of the energy business as mass consumers of food products it is not surprising to see food prices rapidly putting upward pressure on overall inflation."As we see Soft commodities, especially the Livestock, have different driving factors comparing to equities. Consequently, they should be considered as valuable stock portfolios diversifiers. 


\section{Radostaw Kurach}

\section{CONCLUSIONS}

In this study we measured two things. Using the data from the first decade of the XXI century, at first, we have estimated contemporaneous correlations between stocks and different commodity sectors indices to assess their diversification potential. We proved that it is cross-sectoral varying. Then, we analyzed the impact of macroeconomic factors and the obtained results indicated that in case of the best diversifiers (Precious Metals and Livestock) recognized at the earlier stage, the impact of the expected macroeconomic conditions is the least pronounced.

The observed patternsrise some new questions, however. As we only mentioned the case of agflation, this phenomenon definitely needs an indepth research. The analysis of the world demand for biofuels may indicate, if the higher than expected co-movement between Agricultural products and business cycle is only a temporary phenomenon or it is a new regularity. This conclusion should be especially important for global portfolio managers.

\section{LITERATURE}

Anson M.J.P. (2009). CAIA Level I. An Introduction to Core Topics in Alternative Investments.: John Wiley \& Sons, Hoboken, New Jersey.

Artis M., Chouliarakis G., Harischandra P. (2009), Business Cycle Synchronization Since 1880, "Centre for Growth and Business Cycle Research Discussion Paper Series", No.153.

Baxter M., Kouparitsas M. A. (2005),Determinants of business cycle comovement: a robust analysis, "Journal of Monetary EconomicsJanuary", Vol. 52, No. 1.

Bernstein R., Rasco J. (2007), Global Agriculture \&Agflation, Merril Lynch, 27 April 2007. http://www.fullermoney.com/content/2007-05-14/MerrillLynchOn FoodInflation27Apr07.PDF (as on 10 ${ }^{\text {th }}$ Jan 2012).

Camacho M., Perez-Quiros G. (2011), Commodity prices and the business cycle in Latin America: Living and dying by commodities?,http://www.um.es/econo metria/Maximo/articulos/commodities.pdf(as on $10^{\text {th }}$ Jan 2012).

Demidova-Menzel N., Heidorn T. (2007), Gold in the Investment Portfolio, "Frankfurt School-Working Paper Series", No. 87.

Fabozzi F. J., Fuss R., Kaiser D.G. (2008), The Handbook of Commodity Investing, JohnWiley\&Sons, Inc., Hoboken, New Jersey.

Feldstein, M. (1981), The Effect of Inflation on the Prices of Land And Gold, "NBER Working Papers", No. 0296.

Flood R.P., Rose A.K. (2010),Inflation targeting and business cycle synchronization, "Journal of International Money and Finance", Vol. 29, No. 4.

Fritsche U., Marklein F., (2001), Leading Indicators of Euroland Business Cycles, "Discussion Papers of DIW Berlin", No. 238. 
Goldman Sachs \& Co. (1996), The Strategic Case for Using Commodities in Portfolio Diversification, "Goldman Sachs Research Series on Commodities as an Asset Class", July.

Goldman Sachs (2012), S\&P GSCI TM Commodity Index Approach, http://www2.go ldmansachs.com/what-we-do/securities/products-and-businessgroups/products/gsci/approach.html(as on $10^{\text {th }}$ Jan 2012).

Gorton G., Rouwenhorst K. G., (2006), Facts and Fantasies about Commodities Futures, "Financial Analysts Journal", Vol. 62, No. 2.

Greer R. (1997), What is an Asset Class, Anyway?, "The Journal of Portfolio Management", Vol. 23, No. 2.

Greer R. (2000), The Nature of Commodity Index Returns, "Journal of Alternative Investments", Summer.

Grubel H.G. (1968), Internationally Diversified Portfolios: Welfare Gains and Capital Flows, "The American Economic Review", Vol. 58, No. 5.

Gubler M., Hertweck M. S. (2011), Commodity Price Shocks and the Business Cycle: Structural Evidence for the U.S, "Working Paper Series of the Department of Economics, University of Konstanz”, No. 2011-03.

Hess D., Huang H., Niessen-Ruenzi A. (2008), How Do Commodity Futures Respond to Macroeconomic News?, "Financial Markets and Portfolio Management", Vol. 22, No. 2.

Hodrick R., Prescott E.C. (1997), Postwar U.S. Business Cycles: An Empirical Investigation, "Journal of Money, Credit, and Banking", Vol. 29, No. 1.

Idzorek T., (2006), Strategic Asset Allocation and Commodities, Ibbotson Associates, March 27.

Imbs J. (2004),Trade, Finance, Specialization and Synchronization, "Review of Economics and Statistics", Vol. 86, No. 3.

Inklaar R., de Haan J. (2001), Is there really a European business cycle? A comment, "Oxford Economic Papers", Vol. 53, No. 2.

Kaplan P. D., Lummer S. L. (1998), Update: GSCI Collateralized Futures as a Hedging and Diversification Tool for Institutional Portfolios, "The Journal of Investing", Vol. 7, No. 4.

Laws J., Thompson J. (2007), Portfolio Diversification and Commodity Futures, "Liverpool Business School Working Paper", May.

Levy H., Sarnat M. (1970),International Diversification of Investment Portfolios, "The American Economic Review", Vol. 60, No. 4.

Markowitz, H.M. (1952). Portfolio Selection, "The Journal of Finance”, Vol. 7, No 1.

Mohanty J., Singh B., Jain R. (2003), Business cycles and leading indicators of industrial activity in India. Published, "Reserve Bank of India Occasional Papers", Vol. 21.

Niemczak K. (2010), Eastern European Equity Markets and the Subprime Crisis. Does Emerging Europe Still Offer Diversification Benefits?, "e-Finanse", Vol. 6, No. 3.

Samuelson P. (1966), Science and Stock, "Newsweek", September 19.

Sinquefield, R.A. (1996), Where are the gains from international diversification?, "Financial Analysts Journal", Vol. 52, No. 1. 
Standard \& Poor's (2012), S\&P GSCI® Index Factsheet, http://www.standardandp oors.com/indices/articles/en/us/?articleType=PDF\&assetID=1245186878016 (10.01.2012).

Stock J.H., Watson M.W. (1998), Business Cycle Fluctuations in U.S. Macroeconomic Time Series, "NBER Working Paper", No. 6528.

Strategic Investment Solutions (2011), Real Return Assets, "SIS Research Paper", June 2011. 